\title{
Absence of Microsatellite Instability In Soft Tissue Sarcomas
}

\author{
Nathália C. Campanella ${ }^{a}$ Valter Penna ${ }^{b}$ Guilherme Ribeiro ${ }^{c}$ \\ Lucas Faria Abrahão-Machadoc, d Cristovam Scapulatempo-Neto ${ }^{a, b}$ \\ Rui Manuel Reis ${ }^{a}, \mathrm{e}, \mathrm{f}$ \\ ${ }^{\mathrm{a}}$ Molecular Oncology Research Center and Departments of ${ }^{\mathrm{b}}$ Orthopedy, ${ }^{\mathrm{C}}$ Pathology and ${ }^{\mathrm{d}}$ Citogenetic, Barretos \\ Cancer Hospital, Barretos, Brazil; e Life and Health Sciences Research Institute (ICVS), Health Sciences School, \\ University of Minho, Braga, and ' ICVS/3B's - PT Government Associate Laboratory, Braga/Guimarães, Portugal
}

\section{Key Words}

Soft tissue sarcomas - Microsatellite instability ·

DNA repair proteins was not affected, demonstrating that all cases were microsatellite stable. Conclusion: Our results suggest that MSI does not play a role in STS tumorigenesis.

(C) 2015 S. Karger AG, Basel

\section{Introduction}

Soft tissue sarcomas (STS) are a heterogeneous group of mesenchymal neoplasms with distinct histological characteristics that are classified according to the adult tissue they resemble [1-4]. Although STS are relatively rare, accounting for only $0.7 \%$ of adult malignancies and approximately $6.5 \%$ of childhood cancers, effective treatment options remain limited, particularly for advanced disease [1, 5]. In 2014, 12,020 new STS are expected to be diagnosed in the USA, with 4,740 predicted deaths [6].

STS can occur anywhere in the body but they are most common in the extremities (75\%), followed by the trunk (10\%) and the retroperitoneum (10\%) [4]. Histologically, around $75 \%$ of STS are classified as undifferentiated pleo-

\section{KARGER 125}

(c) 2015 S. Karger AG, Basel

$1015-2008 / 15 / 0821-0036 \$ 39.50 / 0$ 
morphic sarcoma (previously denominated by malignant fibrous histiocytoma), liposarcoma, leiomyosarcoma, myxofibrosarcoma, synovial sarcoma, or malignant peripheral nerve sheath tumors [4]. The most common STS subtype in childrens in rhabdomyosarcoma [4]. Despite the different types, they share many clinical and pathological features. The current American Joint Committee on Cancer (AJCC) has established a grading system for STS based on the histological grade, tumor size, and the presence of nodal or distant metastases $[4,7]$.

STSs are generally locally aggressive and have a high risk of recurrence and invasive behavior leading to metastasis [1]. Most STS metastasize hematogenously, most commonly to the lung parenchyma both at presentation and at recurrence [4]. The principal treatment for STS is surgery, with or without radiotherapy [3]. This can cure localized disease in approximately $50 \%$ of patients, but within 2-3 years following diagnosis the remaining $50 \%$ of patients develop metastases [8]. Although several chemotherapy regimens are used for the treatment of metastatic disease, there remains a poor median survival rate of 8-12 months, which has shown little improvement in the last 20 years [8]. Therefore, uncovering the molecular causes of STS could lead to better disease management and/or the development of much needed new therapies.

Genetically, some events have recently gained attention in sarcomas; one of these is the microsatellite instability (MSI) phenotype. MSI was first described in tumors associated with hereditary nonpolyposis colorectal cancer (or Lynch syndrome) [9]. It arises in short repetitive DNA sequences (or microsatellites) due to defects in the DNA mismatch repair (MMR) system, which normally recognizes and repairs errors that occur during DNA replication, as well as repairing some forms of DNA damage $[10,11]$. MSI is defined as altered lengths of repetitive sequences in tumor DNA compared to corresponding normal DNA $[10,11]$. The presence of MSI in some tumor types, particularly in colorectal cancer, appears to be related to specific clinical and histopathological features, including location, tumor lymphocyte infiltration, tumor differentiation, frequency of distant metastasis, and prognosis [12]. Moreover, MSI-positive tumors are prone to accumulate mutations in other genes that harbor microsatellite regions in their coding or regulatory regions, known as MSI target genes [13, 14].

Currently, the determination of MSI phenotype in colorectal cancer tumors can help to predict the therapy response and the prognosis of the patients $[12,15]$. On the other hand, in STS, there are no reliable molecular markers that can predict the prognosis of the STS patients [16]. Because of this and considering the poor characterization of the MSI phenotype, due in part to insufficient and controversial results [17-20], in this work we assessed this phenomenon using accurate MSI methodology, correlating it with loss of MMR protein expression in a series of Brazilian STS.

\section{Materials and Methods}

\section{Subjects}

We analyzed 71 patients with the diagnosis of STS submitted for surgery at the Barretos Cancer Hospital. Relevant clinicalpathological data available included patient's age, race and gender, tumor localization, diagnostic and grade (according to the French Federation of Cancer Centers Sarcoma Group (FNCLCC)) [7], disease progression, presence of pleomorphic cells, presence of metastasis, and disease recurrence, as specified in table 1 . This study was approved by the local ethics committee (CEP$331 / 2010)$.

\section{DNA Isolation}

Paraffin-embedded tumor samples from 71 patients were retrieved from the Pathology Department of Barretos Cancer Hospital. The tissues were deparaffinized by a serial extraction with xylene and ethanol, and selected areas of tumor were macrodissected using a sterile needle. DNA was isolated using the QIAamp ${ }^{\circledR}$ DNA Micro Kit (Qiagen, Hilden, Germany), following the manufacturer's instructions and as previously described by our group [21]. The quality and concentration of DNA were measured using a NanoDrop $2000 \mathrm{U}$-Vis Spectrophotometer, followed by storage at $-20^{\circ} \mathrm{C}$ until molecular analysis.

The DNA from the HCT-15 cancer cell line was extracted using Trizol reagent (Life Technologies, Gaithersburg, Md., USA), following the manufacturer's protocol. HCT-15 was the positive MSI-high (MSI-H) control in all MSI analysis.

\section{MSI Analysis}

The MSI evaluation was performed using multiplex PCR for five quasimonomorphic mononucleotide repeat markers (NR27, NR-21, NR-24, BAT-25, and BAT-26) previously described [22-25]. Briefly, each antisense primer was end-labeled with a fluorescent dye, as follows: FAM (6-carboxyfluorescein) for BAT-26 and NR-21, VIC ( $2^{\prime}$-chloro- $7^{\prime}$-phenyl-1,4-dichloro-6carboxyfluorescein) for BAT-25 and NR-27 and NED (2,7,8-benzo-5-fluoro-2,4,7-trichloro-5-carboxyfluorescein) for NR-24. PCR was performed using the Qiagen Multiplex PCR Kit (Qiagen) with $0.5 \mu \mathrm{l}$ of DNA at $50 \mathrm{ng} / \mu \mathrm{l}$ and the five markers were coamplified in a standard multiplex PCR (denaturation at $95^{\circ} \mathrm{C}$ for $15 \mathrm{~min}$ and $40 \mathrm{cycles}$ of denaturation at $95^{\circ} \mathrm{C}$ for $30 \mathrm{~s}$, annealing at $55^{\circ} \mathrm{C}$ for $90 \mathrm{~s}$ and extension at $72^{\circ} \mathrm{C}$ for $30 \mathrm{~s}$, followed by a final extension at $72^{\circ} \mathrm{C}$ for $40 \mathrm{~min}$ ). PCR products were then submitted to capillary electrophoresis on an ABI $3500 \mathrm{XL} \mathrm{Ge-}$ netic Analyzer (Applied Biosystems, Carlsbad, Calif., USA), according to the manufacturer's instructions, and the results were analyzed using GeneMapper v4.1 software (Applied Biosystems). 
Table 1. Clinical-pathological features of STS patients

\begin{tabular}{|c|c|c|}
\hline Variable & $\mathrm{n}$ & $\%$ \\
\hline \multicolumn{3}{|l|}{ Age, years } \\
\hline$>51$ & 41 & 57.7 \\
\hline$\leq 51$ & 30 & 42.3 \\
\hline \multicolumn{3}{|l|}{ Gender } \\
\hline Female & 27 & 38.6 \\
\hline Male & 43 & 61.4 \\
\hline \multicolumn{3}{|l|}{ Race } \\
\hline Caucasian & 52 & 74.3 \\
\hline Not Caucasian & 18 & 25.7 \\
\hline \multicolumn{3}{|l|}{ Location } \\
\hline Inferior limb & 51 & 71.8 \\
\hline Superior limb & 20 & 28.2 \\
\hline \multicolumn{3}{|l|}{ Diagnostic } \\
\hline Leiomyosarcoma & 12 & 16.9 \\
\hline Pleomorphic leiomyosarcoma & 3 & 4.3 \\
\hline Round cells/myxoid liposarcoma & 4 & 5.6 \\
\hline Myxoid liposarcoma & 5 & 7.1 \\
\hline Round-cell liposarcoma & 2 & 2.8 \\
\hline \multicolumn{3}{|l|}{ High-grade undifferentiated pleomorphic } \\
\hline sarcoma & 11 & 15.5 \\
\hline Monophasic fibrous synovial sarcoma & 6 & 8.5 \\
\hline High-grade myxofibrosarcoma & 5 & 7.0 \\
\hline Malignant peripheral nerve sheath tumor & 7 & 9.9 \\
\hline Low-grade fibromyxoid sarcoma & 1 & 1.4 \\
\hline Poorly differentiated synovial sarcoma & 2 & 2.8 \\
\hline High-grade myofibroblastic sarcoma & 2 & 2.8 \\
\hline Clear cell sarcoma & 1 & 1.4 \\
\hline Biphasic synovial sarcoma & 1 & 1.4 \\
\hline Fibrosarcoma & 1 & 1.4 \\
\hline Angiomatoid histiocytoma & 1 & 1.4 \\
\hline Well-differentiated liposarcoma & 1 & 1.4 \\
\hline Undifferentiated liposarcoma & 1 & 1.4 \\
\hline Pleomorphic liposarcoma & 1 & 1.4 \\
\hline Low-grade myofibroblastic sarcoma & 1 & 1.4 \\
\hline \multicolumn{3}{|l|}{ Giant-cell-rich high-grade undifferentiated } \\
\hline pleomorphic sarcoma & 1 & 1.4 \\
\hline Malignant solitary fibrous tumor & 1 & 1.4 \\
\hline Alveolar sarcoma & 1 & 1.4 \\
\hline \multicolumn{3}{|l|}{ Cellular type } \\
\hline Absence of pleomorphic cells & 39 & 56.5 \\
\hline Presence of pleomorphic cells & 30 & 43.5 \\
\hline \multicolumn{3}{|l|}{ Grade } \\
\hline Low grade $(\mathrm{I})$ & 10 & 14.3 \\
\hline High grade (II or III) & 60 & 85.7 \\
\hline \multicolumn{3}{|l|}{ Disease progression } \\
\hline No & 21 & 31.8 \\
\hline Yes & 45 & 68.2 \\
\hline \multicolumn{3}{|l|}{ Disease recurrence } \\
\hline Absent & 39 & 56.5 \\
\hline Present & 30 & 43.5 \\
\hline \multicolumn{3}{|l|}{ Metastasis } \\
\hline Absent & 34 & 49.3 \\
\hline Present & 35 & 50.7 \\
\hline
\end{tabular}

DNA from the cell line HCT-15 (MSI-H) was used as a positive control for MSI. In a recent study, our group determined the quasimonomorphic variation range of each marker for the Brazilian population [25]. Accordingly, samples were considered MSI-H when two or more markers were altered and MSI-low (MSI-L) when only one marker was altered, with further validation by MSI analysis of normal tissue or immunohistochemistry of the MMR enzymes [25].

\section{MMR Immunohistochemistry}

Formalin-fixed paraffin-embedded tissue specimens were cut into 4- $\mu \mathrm{m}$ sections for immunohistochemistry using the avidinbiotin peroxidase complex method with the Dako EnVision ${ }^{\mathrm{TM}}$ FLEX detection system Kit (Dako) and the Autostainer Link 48 equipment (Dako), in accordance with the manufacturer's instructions. The antigen retrieval process was performed at $97^{\circ} \mathrm{C}$ for $20 \mathrm{~min}(\mathrm{pH}=9.0)$. Endogenous peroxidases were blocked with EnVision FLEX peroxidase-blocking reagent. The primary antibodies (rabbit polyclonal) used in this study were the following: anti-MLH1 (dilution 1:100, clone G168-728, Cellmark); antiMSH2 (dilution 1:100, clone G219-1129, Cellmark); anti-PMS2 (dilution 1:25, clone MRH-28, Cellmark), and anti-MSH6 (dilution 1:600, clone 44, Cellmark). The DAB solution was used for visualization. Slides were counterstained with hematoxylin. $\mathrm{Nu}$ clear immunostaining of normal epithelial cells, lymphocytes and stromal cells served as internal positive controls in each case, and colorectal cancer cases known to exhibit an MSI-H phenotype and known to lack MLH1 and MSH2 served as negative controls [26]. All cases were quantitatively scored as positive (defined as $>10 \%$ of stained nuclei of tumor cells) or negative $(<10 \%$ of stained nuclei of tumor cells), as previously described $[27,28]$. Tumors negative for any of the MMR proteins were classified as MMR-deficient, whereas tumors positive for all MMR proteins were considered MMR-proficient [26, 27].

\section{Results}

In 3 out of 71 patients $(4.2 \%)$, we observed one altered MSI marker (BAT-26) (fig. 1; table 2). Of these 3 patients, 2 were male and 1 was female, with the diagnoses of leiomyosarcoma, pleomorphic leiomyosarcoma and highgrade undifferentiated pleomorphic sarcoma, and all exhibited a high grade histologically (table 2). Since we previously reported that the presence of instability in one marker in the Brazilian population can be due to polymorphic variants associated with African ethnic background [25], we further analyzed these subjects by MMR immunohistochemistry to accurately determine their MSI status. In the 3 cases that exhibited instability in one marker, we detected positivity, with strong immunostaining, for all MMR proteins analyzed (MLH1, MSH2, MSH6, and PMS2; fig. 2), suggesting that the MMR pathway was active. Thus, these findings indicate that all 3 cases were microsatellite stable. 
Table 2. Clinical-pathological and molecular features of the 3 cases with instability in one marker

\begin{tabular}{|c|c|c|c|c|c|c|c|c|c|c|c|c|c|c|}
\hline Case & $\begin{array}{l}\text { age, } \\
\text { years }\end{array}$ & gend & location & diagnostic & grade & NR-27 & NR-21 & NR-24 & BAT-25 & BAT-26 & MLH1 & MSH2 & MSH6 & PMS2 \\
\hline E093102D2 & 46 & $\mathrm{M}$ & SL & HUPS & III & $86 / 87$ & $106 / 106$ & $123 / 123$ & $145 / 146$ & $166^{*} / 178$ & + & + & + & + \\
\hline E1022014 & 41 & $\mathrm{~F}$ & IL & PL & III & $86 / 86$ & $106 / 106$ & $122 / 122$ & $145 / 147$ & $166^{*} / 176$ & + & + & + & + \\
\hline E077056 & 75 & $\mathrm{M}$ & SL & $\mathrm{L}$ & II & $85 / 86$ & $105 / 105$ & $123 / 123$ & $145 / 145$ & $166^{*} / 177$ & + & + & + & + \\
\hline
\end{tabular}

* Marker altered. SL = Superior limb; IL = inferior limb; HUPS = high-grade undifferentiated pleomorphic sarcoma; PL = pleomorphic leiomyosarcoma; $\mathrm{L}=$ leiomyosarcoma.

Fig. 1. Fragment analysis of 1 case with instability (deletion of 8 base pairs) in BAT-26 marker, as indicated by the arrow.

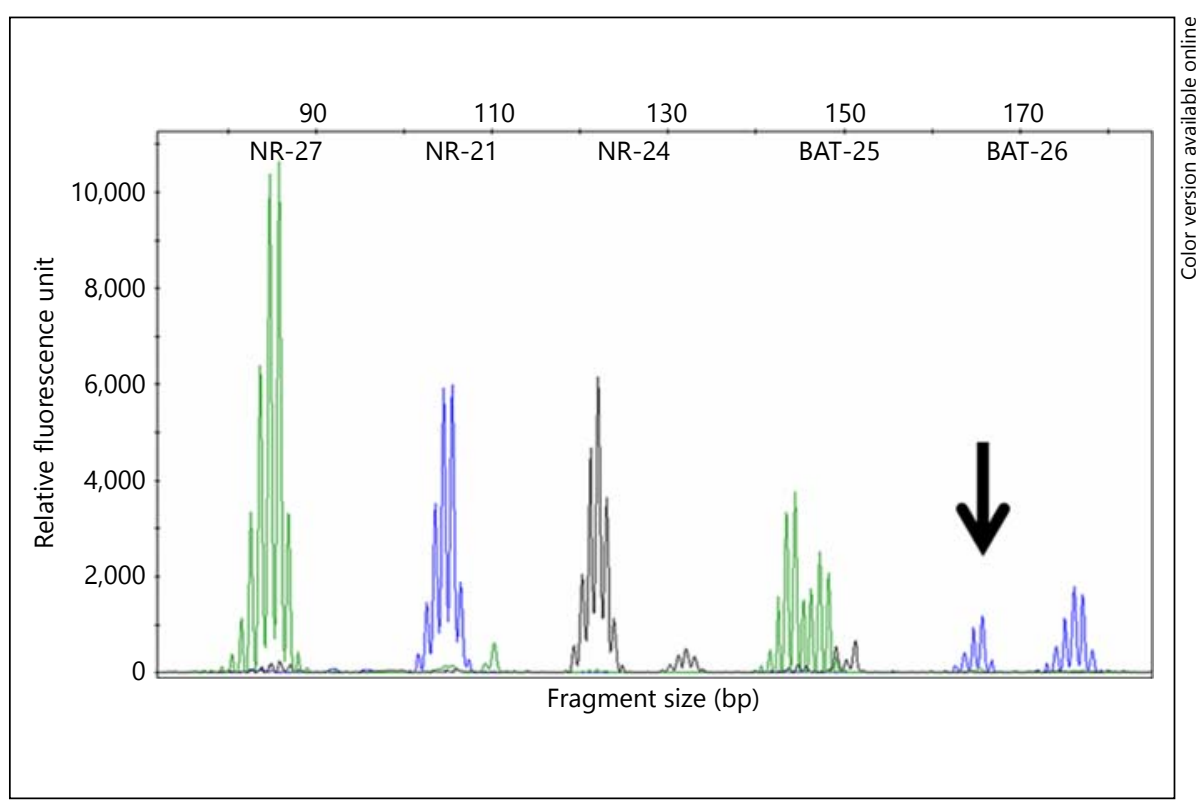

\section{Discussion}

Genetically, several genes have been associated with STS tumorigenesis. The gene amplification of the oncogenes MDM2, N-MYC, ERBB2, and mutations of members of the RAS family are implicated both in the development of STS and with adverse outcomes in STS patients $[3,29]$. Additionally, mutations in TP53 were observed in $25.6 \%$ of STS [30]. Recently, mutations in the TERT gene promoter have also been reported [31]. Despite these findings, there are no effective molecular markers that can predict the prognosis of STS patients.

MSI testing has been used in the discrimination of prognosis in colorectal cancer patients, predicting the therapy response and specific clinical and histopatholog- ical features such as tumor location, lymphocyte infiltration, tumor differentiation, and frequency of distant metastasis [12]. In STS the presence and clinical implication of MSI is largely unknown.

In the present study we analyzed 71 STS cases, using both molecular and immunohistochemistry approaches - the largest study so far to evaluate MSI status using molecular techniques. Sophisticated PCR and capillary electrophoresis techniques with appropriated controls were used and showed no evidence of MSI in these tumors.

The Bethesda panel for MSI evaluation includes five microsatellite loci: two mononucleotides (BAT-25 and BAT-26) and three dinucleotides (D5S346, D2S123 and D17S250) [22]. A following updated international con- 
Fig. 2. Immunohistochemistry of $M M R$ proteins in 1 case with instability in one marker. a Negative control to MLH1. b Negative control to MSH2. c Expression of MLH1. d MSH2. e MSH6. f PMS2. Amplification $\times 200$.
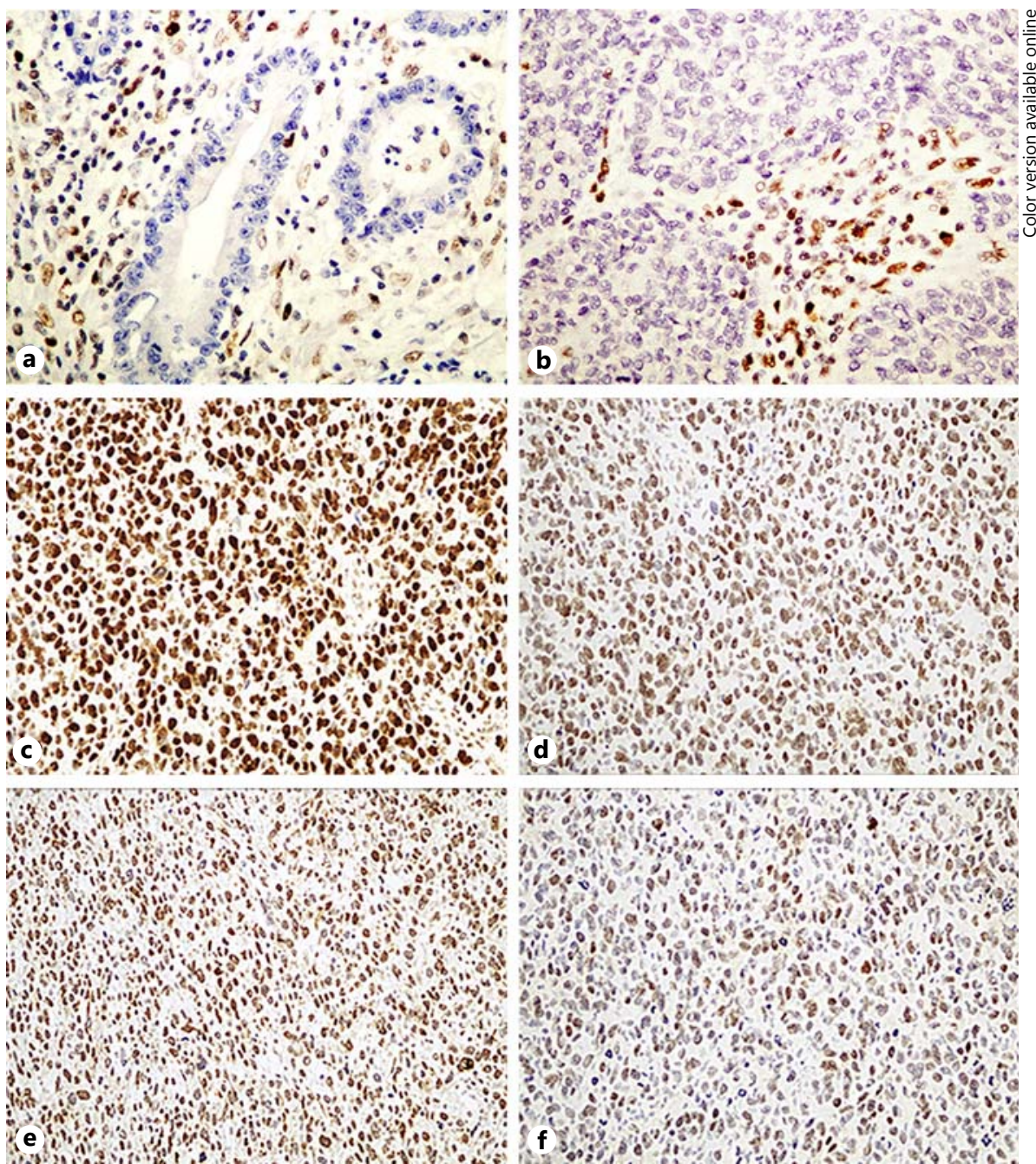

sensus meeting held in December 2002 reevaluated this panel [23] and concluded that there were caveats in its use, and it was recommended that dinucleotide repeats be substituted by mononucleotide repeats $[23,32]$. In the present study we used the newly recommended mononucleotide repeats, which were recently validated by our group for the Brazilian population [25].

The MSI phenotype in STS is poorly characterized, and published results are contradictory (table 3). The first study analyzing MSI in STS was reported in 1994, and the authors observed MSI in $11 \%$ of cases $(2 / 18)$ [17]. Using similar methodologies, Rucinska et al. [18] reported the absence of MSI in 8 cases of low-grade STS and the presence of MSI in 8 high-grade STS cases. The authors found 4 cases with one altered MSI marker, 3 cases with two and 1 case with three altered markers. Furthermore, Kawaguchi et al. [19] studied 40 STS cases and described $25 \%$ of the tumors with the MSI phenotype -2 exhibiting MSI-H and 8 MSI-L. In addition, they reported loss of MLH1 expression in 5 MSI-positive cases (1 MSI-H and 4 MSI-L) and loss of MSH2 expression in $1 \mathrm{MSI}-\mathrm{H}$ case, as well as in 5 microsatellite stable cases (17\%) [19]. In accordance with these results, using immunohistochemistry of MMR proteins, other studies found loss of expression of MSH2 and MSH6 [33], and MLH1 and MSH6 [34] in MSI-positive STS. However, loss of expression of MMR proteins was also observed in microsatellite stable cases, hampering interpretation $[33,34]$.

The discrepancy of our results with those previously published may be due to multiple factors. Firstly, there are many subtypes of STS that may represent different entities and, therefore, have distinct genetic features. Secondly, the number of cases analyzed in previous studies
40

Pathobiology 2015;82:36-42 DOI: $10.1159 / 000369906$
Campanella et al. 
Table 3. Summary of MSI evaluation in STS

\begin{tabular}{|c|c|c|c|c|c|}
\hline Author & Country & $\begin{array}{l}\text { STS analyzed, } \\
\mathrm{n}\end{array}$ & Methodology & Criteria & Conclusion \\
\hline $\begin{array}{l}\text { Wooster } \\
\text { et al. [17], } \\
1994\end{array}$ & $\begin{array}{l}\text { Several } \\
\text { European } \\
\text { countries }\end{array}$ & 18 & $\begin{array}{l}\text { Molecular ( di-, tri- and } \\
\text { tetranucleotide markers) }\end{array}$ & 1 or more markers with instability & $11 \%(2 / 18)$ MSI-positive cases \\
\hline $\begin{array}{l}\text { Saito et } \\
\text { al. [34], } \\
2003\end{array}$ & Japan & 8 & $\begin{array}{l}\text { Immunohistochemistry (MSH2 } \\
\text { and MLH1) }\end{array}$ & Loss of expression & $25 \%(2 / 8)$ MSI-positive cases \\
\hline $\begin{array}{l}\text { Ericson } \\
\text { et al. [33], } \\
2004\end{array}$ & Sweden & 209 & $\begin{array}{l}\text { Immunohistochemistry } \\
\text { (MLH1, MSH2 and MSH6) }\end{array}$ & Loss of expression & $\begin{array}{l}0.9 \%(2 / 209) \text { MSI-positive cases } \\
\text { (loss of MSH2 and MSH6) }\end{array}$ \\
\hline $\begin{array}{l}\text { Rucinska } \\
\text { et al. [18], } \\
2005\end{array}$ & Poland & 16 & $\begin{array}{l}\text { Molecular (di- and } \\
\text { tetranucleotide markers) }\end{array}$ & $\begin{array}{l}\text { MSI-L ( } 1 \text { marker with instability) } \\
\text { and MSI-H ( } 2 \text { or more markers with } \\
\text { instability) }\end{array}$ & $\begin{array}{l}\text { 25\% (4/16) MSI-L and } 18.7 \\
(3 / 16) \text { MSI-H cases }\end{array}$ \\
\hline $\begin{array}{l}\text { Kawaguchi } \\
\text { et al. [19], } \\
2005\end{array}$ & Japan & 40 & $\begin{array}{l}\text { Molecular (dinucleotide markers) } \\
\text { and immunohistochemistry } \\
(\mathrm{MLH} 1 \text { and } \mathrm{MSH} 2)\end{array}$ & $\begin{array}{l}\text { MSI-L ( }<40 \% \text { of markers with instability) } \\
\text { MSI-H ( }>40 \% \text { of markers with instability) }\end{array}$ & $\begin{array}{l}20 \%(8 / 40) \text { MSI-L and } 5 \% \\
(2 / 40) \text { MSI-H cases } \\
\text { MSI-L ( } 4 \text { loss of MLH1) and } \\
\text { MSI-H ( } 1 \text { loss of MLH1) }\end{array}$ \\
\hline $\begin{array}{l}\text { Present } \\
\text { article }\end{array}$ & Brazil & 71 & $\begin{array}{l}\text { Molecular (mono- and dinucleotide } \\
\text { markers) and immunohistochemistry } \\
\text { (MLH1, MSH2, MSH6, and PMS2) }\end{array}$ & $\begin{array}{l}\text { MSI-L (1 marker altered) and MSI-H } \\
\text { ( } 2 \text { or more markers altered) }\end{array}$ & MSS \\
\hline
\end{tabular}

was small. Here, we analyzed 71 STS cases - the largest study so far to evaluate MSI status using molecular techniques. Thirdly, distinct methodologies were used for MSI assessment, and it is well known that the accuracy of MSI detection is highly dependent on the techniques used. In our study we used the gold standard panel of MSI markers widely used in colorectal cancer MSI testing $[9,22,25]$.

In conclusion, our study suggests that MSI does not play a role in STS tumorigenesis.

\section{Acknowledgments}

This project was partially supported by a $\mathrm{CNPq}$ Universal Grant (476192/2013-7) to Rui Manuel Reis. Nathália Cristina Campanella is the recipient of an FAPESP Doctoral Fellowship (2013/25787-3).

\section{Disclosure Statement}

The authors declare no competing financial interests.

\section{References}

$>1$ Weiss's SWG Jr: Enzinger and Weiss's Soft Tissue Tumors, ed 5. Philadelphia, Elsevier, 2008.

2 Brennan MF, Alektiar KM, Maki RG: Soft tissue sarcoma; in DeVita VT, Hellman S, Rosenberg SA (eds) Cancer: Principles and Practice of Oncology. Philadelphia, Lippincott Williams \& Wilkins, 2001, pp 1844-1891.

$\checkmark 3$ Cormier JN, Pollock RE: Soft tissue sarcomas. CA Cancer J Clin 2004;54:94-109.

4 Fletcher CDM, Bridge JA, Hogendoorn PCW, Mertens F: WHO Classification of Tumors of Soft Tissue and Bone, ed 4. Geneva, WHO, 2013.

$>5$ Siegel R, et al: Cancer statistics, 2011: the impact of eliminating socioeconomic and racial disparities on premature cancer deaths. CA Cancer J Clin 2011;61:212-236.

6 American Cancer Society. http://www.cancer. org/cancer/sarcoma-adultsofttissuecancer/ detailedguide/sarcoma-adult-soft-tissuecancer-key-statistics, 2014.

7 Coindre JM: Grading of soft tissue sarcomas: review and update. Arch Pathol Lab Med 2006;130:1448-1453.

$>8$ Blay JY: A decade of change in the treatment of advanced soft tissue sarcoma. Expert Rev Anticancer Ther 2013;13(6 suppl 1): S1-S2.

-9 Boland CR, Goel A: Microsatellite instability in colorectal cancer. Gastroenterology 2010 138:2073-2087.e3.
0 Miquel C, et al: Frequent alteration of DNA damage signalling and repair pathways in human colorectal cancers with microsatellite instability. Oncogene 2007;26:5919-5926.

-11 Young J, et al: Features of colorectal cancers with high-level microsatellite instability occurring in familial and sporadic settings: parallel pathways of tumorigenesis. Am J Pathol 2001;159:2107-2116.

12 Sinicrope FA, Sargent DJ: Molecular pathways: microsatellite instability in colorectal cancer: prognostic, predictive, and therapeutic implications. Clin Cancer Res 2012;18:1506-1512.

13 Alhopuro P, et al: Candidate driver genes in microsatellite-unstable colorectal cancer. Int J Cancer 2012;130:1558-1566. 
14 Mori Y, et al: Instabilotyping: comprehensive identification of frameshift mutations caused by coding region microsatellite instability. Cancer Res 2001;61:6046-6049.

$\checkmark 15$ Laghi L, Malesci A: Microsatellite instability and therapeutic consequences in colorectal cancer. Dig Dis 2012;30:304-309.

16 Takahashi A, et al: Analysis of gene expression profiles of soft tissue sarcoma using a combination of knowledge-based filtering with integration of multiple statistics. PLoS One 2014;9:e106801.

17 Wooster R, et al: Instability of short tandem repeats. Nat Genet 1994;6:152-156.

18 Rucinska M, et al: High-grade sarcomas are associated with microsatellite instability (chromosome 12) and loss of heterozygosity (chromosome 2). Med Sci Monit 2005;11: BR65-BR68.

19 Kawaguchi K, et al: Microsatellite instability and hMLH1 and hMSH2 expression analysis in soft tissue sarcomas. Oncol Rep 2005; 13 : 241-246.

20 Monument MJ, et al: Microsatellite instability in sarcoma: fact or fiction? ISRN Oncol 2012; 2012:473146.
21 Basto D, et al: Mutation analysis of B-RAF gene in human gliomas. Acta Neuropathol 2005; 109:207-210.

22 Buhard O, et al: Multipopulation analysis of polymorphisms in five mononucleotide repeats used to determine the microsatellite instability status of human tumors. J Clin Oncol 2006;24:241-251

23 Buhard O, et al: Quasimonomorphic mononucleotide repeats for high-level microsatellite instability analysis. Dis Markers 2004;20 251-257.

24 Viana-Pereira M, et al: Microsatellite instability in pediatric high grade glioma is associated with genomic profile and differential target gene inactivation. PLoS One 2011;6:e20588.

25 Campanella NC, et al: Optimization of a pentaplex panel for MSI analysis without control DNA in a Brazilian population: correlation with ancestry markers. Eur J Hum Genet 2014;22:875-880.

26 Yamane LS, et al: KRAS and BRAF mutations and MSI status in precursor lesions of colorectal cancer detected by colonoscopy. Oncol Rep 2014;32:1419-1426.

27 Bertagnolli MM, et al: Microsatellite instability predicts improved response to adjuvant therapy with irinotecan, fluorouracil, and leucovorin in stage III colon cancer: Cancer and Leukemia Group B Protocol 89803. J Clin Oncol 2009;27:1814-1821.
28 Lanza G, et al: Immunohistochemical test for MLH1 and MSH2 expression predicts clinical outcome in stage II and III colorectal cancer patients. J Clin Oncol 2006;24:23592367.

29 Levine EA: Prognostic factors in soft tissue sarcoma. Semin Surg Oncol 1999;17:23-32.

30 Yin L, et al: Mutational analysis of p53 and PTEN in soft tissue sarcoma. Mol Med Rep 2012;5:457-461.

31 Vinagre J, et al: Frequency of TERT promoter mutations in human cancers. Nat Commun 2013;4:2185.

32 Suraweera N, et al: Evaluation of tumor microsatellite instability using five quasimonomorphic mononucleotide repeats and pentaplex PCR. Gastroenterology 2002;123:18041811.

33 Ericson K, et al: Immunohistochemical loss of the DNA mismatch repair proteins $\mathrm{MSH} 2$ and MSH6 in malignant fibrous histiocytomas. Sarcoma 2004;8:123-127.

34 Saito T, et al: Possible association between tumor-suppressor gene mutations and hMSH2/hMLH1 inactivation in alveolar soft part sarcoma. Hum Pathol 2003;34: 841-849. 